Technical Note

\title{
Biodiesel from different oil using fixed-bed and plug-flow reactors
}

\author{
Pengmei Lu*, Zhenhong Yuan, Lianhua Li, Zhongming Wang, Wen Luo \\ Key Laboratory of Renewable Energy and Gas Hydrate, Guangzhou Institute of Energy Conversion, Chinese Academy of Sciences, No. 2 Nengyuan Road, Wushan, \\ Tianhe, Guangzhou 510640, China
}

\section{A R T I C L E I N F O}

\section{Article history:}

Received 21 November 2007

Accepted 20 July 2009

Available online 12 August 2009

\section{Keywords:}

Biodiesel

Plug-flow

Fixed-bed

Rapeseed oil

Chinese wood oil

Trap grease

\begin{abstract}
A B S T R A C T
In this study, a pilot scale of $100 \mathrm{t} /$ year biodiesel production system, mainly consisting of a fixed-bed and a down-stream plug-flow reactors, was setup to test different feedstock oils, especially a kind of highacidified oil, trap grease, for their feasibility as biodiesel feedstock in China. The tested oils include three kinds of typical oil from Guangdong Province, China: rapeseed oil, Chinese wood oil, and trap grease. At the same time the optimum residence time for a plug-flow reactor to perform transesterification reaction was investigated in this study. At the temperature of $65^{\circ} \mathrm{C}$, methanol/oil molar ratio of $6: 1$ and $\mathrm{KOH}$ load of $1.2 \mathrm{wt} \%$ of oil, the optimum residence time was found to be $19 \mathrm{~min}$. A type of ion-exchange resin was used to fill in the fixed-bed reactor and used as the esterification catalyst for pretreating on the highacidified oil. For the fresh catalyst, the acid value of trap grease could be reduced from $114 \mathrm{mg} \mathrm{KOH} / \mathrm{g}$ to about $2 \mathrm{mg} \mathrm{KOH} / \mathrm{g}$ after $13 \mathrm{~h}$ at temperature $75^{\circ} \mathrm{C}$, catalyst load of $15 \mathrm{wt} \%$ of oil, methanol addition of $20 \mathrm{wt} \%$ of oil. The lifetime test for the catalyst indicated that its life is over 30 days. The quality of biodiesel derived from three feedstock oils is compared with newly published China BD100 standard of GB/T20828-2007. A comparison of the results reveals that the biodiesel generated through this system could satisfactorily meet China BD100 standard. It indicates that the designed process in this system has a good adaptability for different kinds of oil.
\end{abstract}

(c) 2009 Elsevier Ltd. All rights reserved.

\section{Introduction}

The concerns of energy supply security, soaring-up fuel prices, worsening environment, global warming, and sustainable development are enormous in a fast developing country such as China. They can only be answered by solutions that match them in reach and vision. Biodiesel is emerging as a promising solution to these concerns in China. Though it is still in its infancy with small capacity, but it is expected to accelerate in coming years because the Chinese government is attaching more and more importance to it. The national biodiesel standard of GB/T20828-2007 for BD100 came into force in May, 2007. In this standard, 16 specifications are determined.

For China, the most important key factor driving or limiting biodiesel development is feedstock supply. So far, in China, virgin oil feedstocks are not economically feasible for biodiesel production due to their high cost, and the existing feedstocks for biodiesel are all waste grease and oils [1-3].

\footnotetext{
* Corresponding author. Tel.: +86 20 87057760; fax: +86 2087057737

E-mail address: lvpm@ms.giec.ac.cn (P. Lu).
}

In China, more edible oils are consumed than in any other country in the world. Due to the cooking and eating habits of the Chinese people, a great deal of waste oil and grease is produced from the food processing industry.

As per official data, 19.14 million tons were consumed in 2005. The average individual consumption level of edible oil is $13.6 \mathrm{~kg} /$ person in 2005 and $17 \mathrm{~kg} /$ person in big cities. It is estimated that at least 3 million tons of waste oil and grease are produced in China annually and of this at least 2 million tons could be recovered and processed into biodiesel [4].

As Kulkarni and Dalai [5] pointed out, waste cooking oil is an economical source for biodiesel and Zhang et al. [6] reported that approximately $120000 \mathrm{t} /$ year of yellow grease is produced in Canada.

Although much literature has addressed the research on biodiesel conversion from high free fatty acid (FFA) oil [5,7-11], the acid value of China's waste oil is much higher compared to that of other countries, which makes it more difficult to convert this rather high FFA oil to biodiesel in China.

Due to the fact that the existing biodiesel factories in China are all almost based on waste grease and oil feedstocks, which have a high acid value or FFA content, the major biodiesel process technology adopted in China is non-consecutive 2-step process, 
which still has some problems yet to be solved, such as low efficiency, serious environmental pollution. Therefore, in order to solve the above-mentioned problems, a consecutive process, consisting of fixed-bed reactor together with a down-stream plug-flow reactor has been setup in the present study.

Because of the special condition of China, that is only $4 \%$ arable land, while $69 \%$ mountainous land, tableland and hilly land and $17 \%$ of water areas (lakes, rivers, offshore sea), many specialists have pointed out that, for a long-term development of biodiesel, China must resort to mass plantation of energy crops on mountain areas.

At the current time, the feedstock for China's biodiesel production is a combination of waste oil, plant oil and other oils.

Thus on this pilot scale system, different feedstocks, including rapeseed oil, Chinese wood oil, trap grease are tested and evaluated based on the experimental results.

\section{Experimental section}

\subsection{Feed materials and catalyst}

Three kinds of typical feed oils: rapeseed oil, Chinese wood oil, trap grease are selected as the test oils for comparison. Rapeseed oil was bought from the commercial market in Guangzhou. Chinese wood oil is derived from a kind of wild oil plant, which grows extensively on the mountains of south Guangdong Province, China. The seed kernel oil content of this oil plant can reach as high as $58.6 \mathrm{wt} \%$. Trap grease was obtained from restaurants in Guangzhou city, Guangdong Province, China. The basic properties of these three kinds of oils are shown in Table 1.

From Table 1, it is observed that because of high free fatty acid content in trap grease its relative molecular weight is much smaller than that of virgin oils.

The catalyst used is a kind of ion-exchange resin, bought from a company in Zhejiang Province, China, and its physical and chemical properties are presented in Table 2.

\subsection{Apparatus}

A pilot scale of $100 \mathrm{t} / \mathrm{year}$ biodiesel production system, mainly consisting of a fixed-bed and a down-stream plug-flow reactors, was setup to test the different feedstock oils, in particular a type of high-acidified oil, and trap grease, for their feasibility as biodiesel feedstock in China. As Fig. 1 shows, this system includes 4 main parts. The first is a fixed-bed reactor, in which solid acid catalyst is used to pretreat the oil having high acid value. After the acid value of the oil is decreased to below $5 \mathrm{mg} / \mathrm{KOH}$ through esterification reaction in the fixed-bed reactor, it enters further into the downstream plug-flow reactor for transesterification reaction. This reactor has a distinguishing feature, that is, it has a big ratio of length vs. diameter. By applying plug-flow reactor, the transesterification reaction can be continuously realized in a short residence time with a fast reaction speed. After the fixed-bed and

Table 1

The properties of different feedstock oils.

\begin{tabular}{lllc}
\hline & Rapeseed oil & Chinese wood oil & Trap grease \\
\hline Density/g/ml, $20^{\circ} \mathrm{C}$ & 0.91 & 0.94 & 0.88 \\
Saponification value/mg KOH/g & 192.7 & 194.3 & 151.63 \\
Acid value/mg KOH/g & 0.40 & 7.12 & 114.03 \\
Fatty acid glycerol ester/\% & 97.29 & 95.63 & 40.98 \\
Relative molecular weight & 869.8 & 807 & 443.2 \\
Water content/\% & 0.05 & 0.10 & 0.19 \\
Impurity/\% & No & No & 3.00 \\
\hline
\end{tabular}

Table 2

Physical and chemical properties of ion-exchange resins.

\begin{tabular}{ll}
\hline Items & Value \\
\hline Function group & $\mathrm{SO}^{3-}$ \\
Ion & $\mathrm{H}^{+}$ \\
Particle size $(\mathrm{mm})$ & $0.40-1.25$ \\
Hole volume $(\mathrm{ml} / \mathrm{g})$ & $0.3-0.36$ \\
Specific surface area $\left(\mathrm{m}^{2} / \mathrm{g}\right)$ & $35-40$ \\
Maximum work temperature $\left({ }^{\circ} \mathrm{C}\right)$ & 120 \\
Swelling degree $(\%)$ & $30-50$ \\
Water content $(\%)$ & $3-5$ \\
\hline
\end{tabular}

plug-flow reactors, a biodiesel refining system is installed, which constitutes of glycerol separation through a patented phase splitter [12], coarse biodiesel water washing and biodiesel distillation process.

\subsection{Analysis method}

The biodiesel was analyzed on a HP4890D gas chromatography (GC) with a SE-52 capillary column with detector being FID, and nitrogen as the carrier gas. The methyl ester was dissolved into the chloroform, and the GC work parameters were as follows: the setting temperature of the injection port and the detector was $220^{\circ} \mathrm{C}$ and $275^{\circ} \mathrm{C}$, respectively. The temperature for the oven operated in this program: start at $150{ }^{\circ} \mathrm{C}(1 \mathrm{~min})$, ramp at 20 $225^{\circ} \mathrm{C}(5 \mathrm{~min}), \operatorname{ramp} 5-250^{\circ} \mathrm{C}(2 \mathrm{~min})$.

The quality of biodiesel derived from different oils was analyzed according to the method demanded by GB/T20828-2007 standard.

To assure the reliability of the experimental results, every operating condition was repeated twice and the experimental results presented here are the average values.

\section{Results and discussion}

\subsection{Rapeseed oil test results in the plug-flow reactor}

Plug-flow reactor has not often been employed in biodiesel production; therefore some questions need to be investigated, for instance, flow velocity determination. A too fast flow velocity will result in a too short residence time which then causes incomplete reaction. A too slow flow velocity will cause laminated flow inside the reactor and a turbulent flow is not formed; therefore a uniform mixture of the reaction solution will not be produced. These two conditions will cause a decreased biodiesel conversion rate. Therefore this study explored the optimal residence time for the biodiesel conversion in a plug-flow reactor.

Rapeseed oil was mixed with methanol with a molar ratio 1:6 and $1.2 \mathrm{wt} \%$ of $\mathrm{KOH}$ was used as the catalyst. The reaction temperature remains at $65^{\circ} \mathrm{C}$. Different residence time was realized through changing the feeding frequency of the pump. The experimental results are shown in Fig. 2.

It can be seen from Fig. 2 that: as residence time increases, the conversion rate first climbs up and then goes down. At the residence time of $19 \mathrm{~min}$, the maximum conversion rate of $91.7 \%$ is obtained. This indicates that at an optimal residence time, the reaction reagents inside the reactor mix well and go ahead in a steady turbulent status, which results in a complete conversion. Besides, as investigated [13], transesterification reaction is reversible, during the process, 3 reactions occur subsequently as equations (1)-(3) show. Thus, excess reaction time is not necessary for this process. 


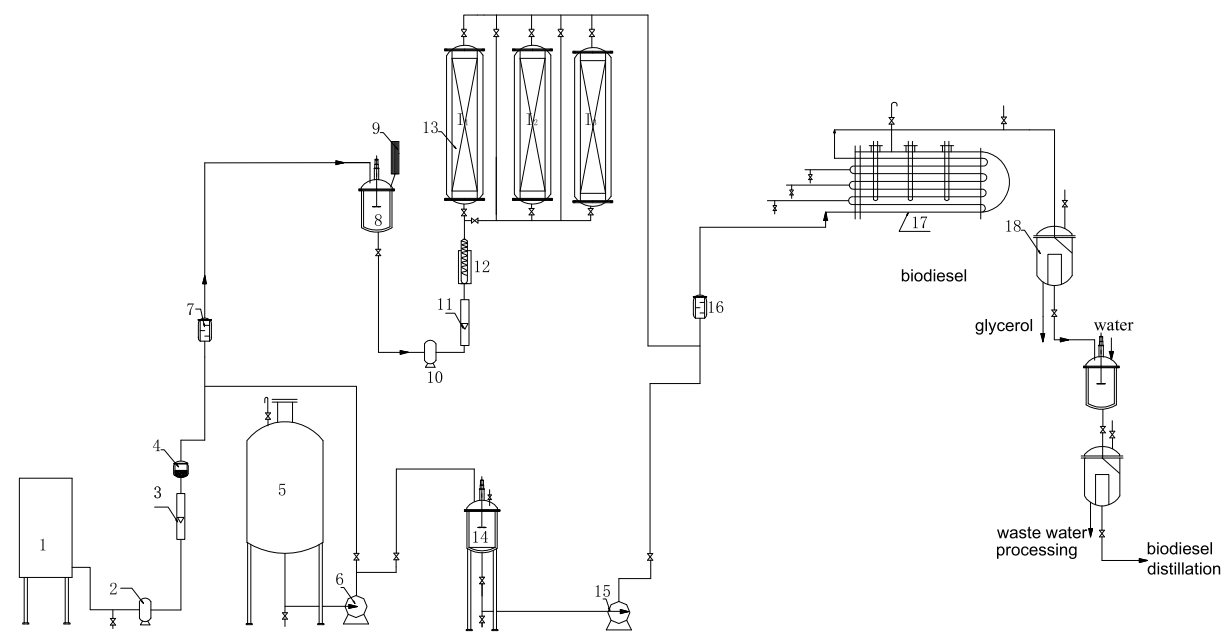

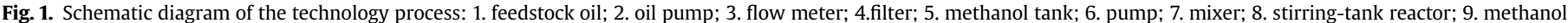
refluence; 10. pump; 11. flowmeter; 12. preheator; 13. fixed-bed reactor; 14. KOH-methanol tank; 15 . pump; 16. mixer; 17. plug-flow reactor; 18. separator.

$\mathrm{TG}+\mathrm{CH}_{3} \mathrm{OH} \leftrightarrow \mathrm{DG}+\mathrm{RCOOCH}_{3}$

$\mathrm{DG}+\mathrm{CH}_{3} \mathrm{OH} \leftrightarrow \mathrm{MG}+\mathrm{RCOOCH}_{3}$

$\mathrm{MG}+\mathrm{CH}_{3} \mathrm{OH} \leftrightarrow \mathrm{GL}+\mathrm{RCOOCH}_{3}$

Where TG, DG and MG represent triglyceride, diglyceride and monoglyceride, respectively and their structures are shown in Fig. 3. GL and $\mathrm{R}$ represent glycerine and fatty acids chains, respectively.

\subsection{Effect of residence time for Chinese wood oil test results}

In the fixed-bed reactor, under the conditions of reaction temperature of $65^{\circ} \mathrm{C}$, methanol/oil ratio of $8: 1$ and a fixed catalyst load, the pretreatment on the Chinese wood oil was performed. Changing the flow rate of feedstock oil, different residence time was obtained. The variation of acid value and corresponding esterification conversion with the residence time is shown in Fig. 4.

The acid value was reduced from $7.02 \mathrm{mg} \mathrm{KOH} / \mathrm{g}$ to $1.28 \mathrm{mg}$ $\mathrm{KOH} / \mathrm{g}$ when the residence time was as long as $45 \mathrm{~min}$. However, as seen in Fig. 4, from time 45 min to time 90 min, the acid value only

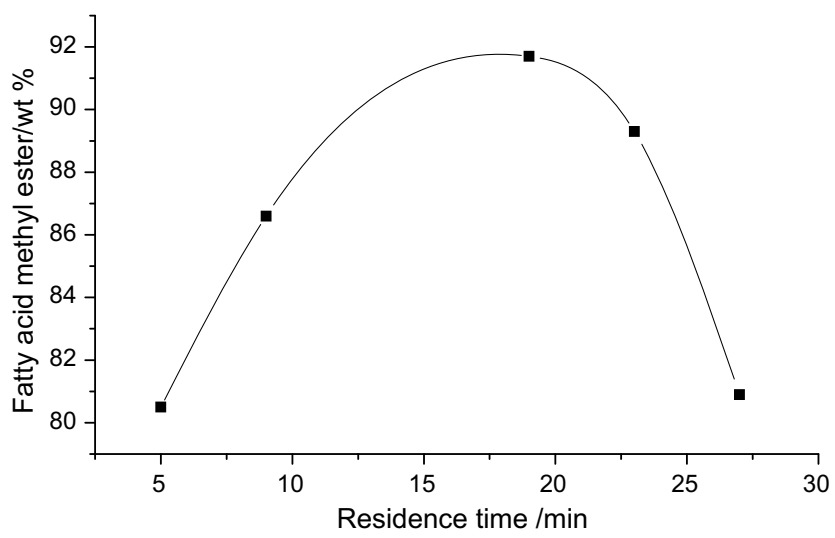

Fig. 2. Optimum residence time determination for plug-flow reactor in transesterification conversion. decreased a little. This can be explained by that: as reaction (4) denotes, esterification reaction between free fatty acid and methanol is reversible; when the reaction time is long enough, the hydrolysis reaction of fatty acid ester will strengthen to generate more fatty acid ester and water. This causes the acid value to reduce with much resistance when it is at a relative low value.

$$
\mathrm{RCOOH}+\mathrm{CH}_{3} \mathrm{OH} \leftrightarrow \mathrm{RCOOCH}_{3}+\mathrm{H}_{2} \mathrm{O}
$$

Where $\mathrm{R}$ represents fatty acids' chains.

Thus, from an economical point of view, it reveals that it is not necessary to spend a long time to decrease the acid value of acidified oil, such as below $1 \mathrm{mg} \mathrm{KOH} / \mathrm{g}$, when the acid value has been reduced enough to avoid saponification in transesterification reaction.

\subsection{Trap grease test results and lifetime test of solid acid catalyst}

The pretreatment on the trap grease was performed in the stirring-tank reactor. Because of the high content of free fatty acid in trap grease, in the process of esterification reaction for pretreatment, a lot of water will be produced and affect the esterification reaction. Then in the stirring-tank reactor, oil sample was taken at an interval of $1 \mathrm{~h}$ and the water and methanol were removed every third hour. And at temperature of $75^{\circ} \mathrm{C}$, catalyst load of $15 \mathrm{wt} \%$ of oil, methanol addition of $20 \mathrm{wt} \%$ of oil, the pretreatment on the trap grease was performed. Fig. 5 shows the experimental results, as well as the lifetime test result for solid acid catalyst. Fig. 5 indicates that for the fresh catalyst, the acid value of trap grease could be reduced from $114 \mathrm{mg} \mathrm{KOH} / \mathrm{g}$ to about $2 \mathrm{mg}$ $\mathrm{KOH} / \mathrm{g}$ after $13 \mathrm{~h}$.

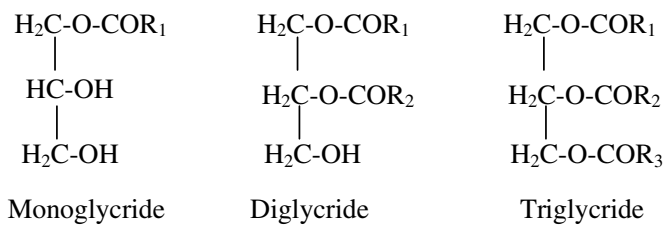

Fig. 3. Structures of mono-, di- and triglycerides, where R1, R2 and R3 represent the fatty acids chains. 


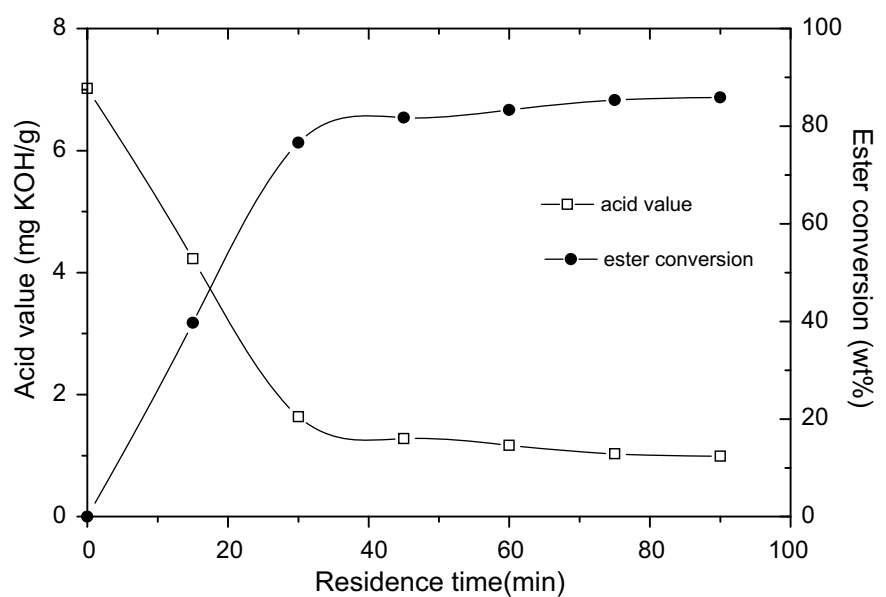

Fig. 4. Effect of residence time on acid value and esterification rate.

As Fig. 5 shows, the acid value drops sharply when it is at a relative high value but reduces much more slowly when reaching a relative small value. This can be explained by: the main reaction (4) occurring in the process being reversible, when more and more fatty acid methyl ester and water are produced, the reaction will move faster to the left side, which results in a slower drop of acid value.

The lifetime test for the solid acid catalyst was continued as long as its activity was obviously falling. It can be seen from Fig. 5 that after 30 days, the activity of this catalyst decreased considerably.

After the stirring-tank reactor, the water and excess $\mathrm{KOH}$ were removed, and $0.5 \mathrm{wt} \%$ of $\mathrm{KOH}$ and $15 \mathrm{wt} \%$ of methanol were added to the reactants and the transesterification reaction proceeded in the plug-flow reactor at $65^{\circ} \mathrm{C}$.

After glycerol separation, water washing and distillation, the new-made trap grease biodiesel was analyzed on the gas chromatograph. Fig. 6 shows the analysis results. Fig. 6 shows that the main components in trap grease biodiesel are methyl hexadecanoate, methyl linoleate, methyl oleate, methyl stearate.

\subsection{Biodiesel properties derived from different feedstock oils}

Table 3 lists the specification values of biodiesel derived from 3 feedstock oils, as well as the 2007 promulgated China BD100 standard. Because of the diversity and complexity of feedstock oils in China, the feedstock oil related cold filter plugging point is not

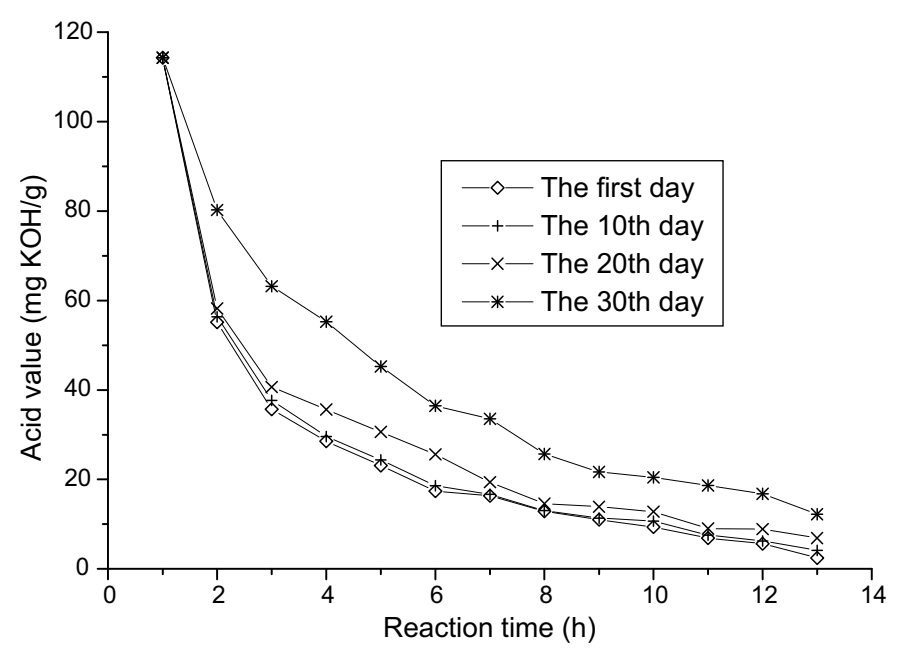

Fig. 5. Trap grease test results and lifetime test of solid acid catalyst.

limited to a specific value in its biodiesel standard. Through mass balance calculation, the biodiesel yield from three kinds of feedstock oils was obtained and also listed in Table 3.

From Table 3, it can be seen that all the specification values of three biodiesel samples meet the China BD100 standard.

As observed in Table 3, the kinematic viscosity value of trap grease biodiesel is the highest among the three kinds of biodiesel, which may be caused by the higher free glycerol and total glycerol content. The residual glycerol and glycerol ester in biodiesel will cause biodiesel viscosity to increase as their viscosity is much larger than that of biodiesel. Further, the content of free glycerol and glyceryl ester content is determined by the perfectness of the processing technology. Hence, a good process should secure the reaction to be successfully completed.

As indicated in Table 3, the Chinese wood oil has a much low biodiesel yield. This is because, during the distillation process, the main component of Chinese wood oil, unsaturated 3,a-elaeostearic acid will experience polymerization reaction and will lower biodiesel yield. Therefore for biodiesel generation from Chinese wood oil, polymerization inhibitor is required to improve biodiesel yield [14]. In other words, Chinese wood oil is not so suitable for biodiesel production.

From Table 3, it can be seen that much of the animal fat in trap grease results in a higher cold filter plugging point of biodiesel.

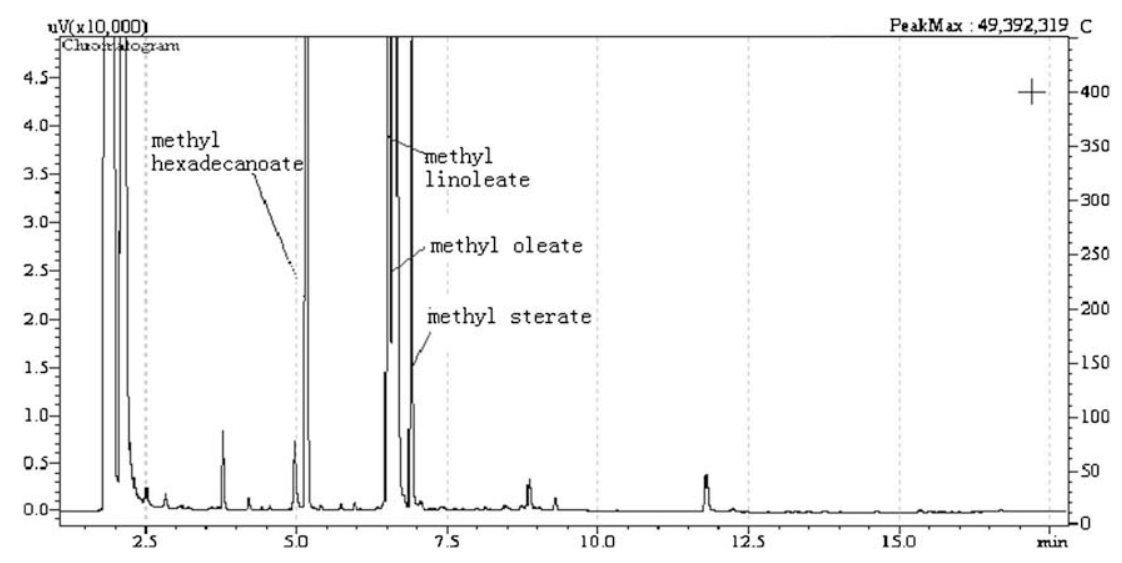

Fig. 6. Chromatograph analysis of trap grease biodiesel. 
Table 3

Properties of biodiesel products derived from different feedstock oils.

\begin{tabular}{|c|c|c|c|c|c|}
\hline \multirow[t]{2}{*}{ Specifications } & \multirow[t]{2}{*}{ Chinese wood oil } & \multirow[t]{2}{*}{ Rapeseed oil } & \multirow[t]{2}{*}{ Trap grease biodiesel } & \multicolumn{2}{|l|}{ GB/T20828-2007 } \\
\hline & & & & S500 & S50 \\
\hline Density, $\mathrm{kg} / \mathrm{m}^{3}\left(20^{\circ} \mathrm{C}\right)$ & 873 & 867 & 890 & $820-900$ & \\
\hline Kinematic viscosity, $\mathrm{mm}^{2} / \mathrm{s}\left(40^{\circ} \mathrm{C}\right)$ & 3.58 & 2.04 & 5.28 & $1.9-6.0$ & \\
\hline Closed flash point, ${ }^{\circ} \mathrm{C}$ & 210 & 185 & 178 & $\geq 130$ & \\
\hline Cold filter plugging point (CFPP), ${ }^{\circ} \mathrm{C}$ & 1 & 0 & 15 & Reported value & \\
\hline Sulfur content, $\%$ & 0.004 & 0.002 & 0.01 & $\leq 0.05$ & $\leq 0.005$ \\
\hline $10 \%$ carbon residue, $\%$ & 0.16 & 0.15 & 0.84 & $\leq 0.3$ & \\
\hline Sulfate ash content & 0.01 & 0.01 & 0.02 & $\leq 0.02$ & \\
\hline Water content, wt $\%$ & 0.03 & 0.02 & 0.04 & $\leq 0.05$ & \\
\hline Mechanical impurity & No & No & No & No & \\
\hline Copper corrosion $\left(50^{\circ} \mathrm{C}, 3 \mathrm{~h}\right)$ & $\leq$ No. 1 grade & $\leq$ No.1 grade & $\leq$ No.1 grade & $\leq$ No.1 grade & \\
\hline Cetane number & 68 & 64 & 60 & $\geq 49$ & \\
\hline Oxidation stability $\left(110^{\circ} \mathrm{C}\right), \mathrm{h}$ & 6.3 & 6.5 & 7.0 & $\geq 6.0$ & \\
\hline Acid value, $\mathrm{mg} \mathrm{KOH} / \mathrm{g}$ & 0.67 & 0.10 & 0.76 & $\leq 0.8$ & \\
\hline Free glycerol, wt\% & 0.004 & 0.003 & 0.005 & $\leq 0.02$ & \\
\hline Total glycerol, wt $\%$ & 0.19 & 0.20 & 0.22 & $\leq 0.24$ & \\
\hline $90 \%$ recycle temperature, ${ }^{\circ} \mathrm{C}$ & 307 & 309 & 320 & $\leq 360$ & \\
\hline Biodiesel yield, wt\% & 50 & 90 & 80 & - & \\
\hline
\end{tabular}

Therefore, pour-point depressant should be added before trap grease biodiesel could be used.

\section{Conclusions}

A pilot scale of $100 \mathrm{t} /$ year biodiesel production system, mainly consisting of a fixed-bed and a down-stream plug-flow reactors, was setup to test three kinds of typical feed oils, rapeseed oil, Chinese wood oil, trap grease for their feasibility as biodiesel feedstock in China.

Because plug-flow reactor is a relatively new technology employed in biodiesel production, its optimal residence time for biodiesel conversion has been investigated. It is found to be about 19 min under the condition of rapeseed oil as feedstock, temperature of $65{ }^{\circ} \mathrm{C}$, molar ratio of $6: 1$ and $\mathrm{KOH}$ load of $1.2 \mathrm{wt} \%$ of oil. In the fixed-bed reactor, using an ion-exchange resin, the pretreatment for Chinese wood oil was performed. According to the investigation result, it was concluded that from an economical point of view, it is not necessary to spend a much longer time to decrease the acid value of acidified oil, such as below $1 \mathrm{mg} \mathrm{KOH} / \mathrm{g}$, when the acid value has been reduced to sufficiently low value and will not cause saponification in subsequent transesterification reaction.

For trap grease having high acid value, in the stirring-tank reactor, at temperature of $75^{\circ} \mathrm{C}$, an optimum catalyst load of $15 \mathrm{wt} \%$ of oil, methanol addition being $20 \mathrm{wt} \%$ of oil, the pretreatment for trap grease was performed. The result indicates that for the fresh catalyst, the acid value of trap grease could be reduced from $114 \mathrm{mg}$ $\mathrm{KOH} / \mathrm{g}$ to about $2 \mathrm{mg} \mathrm{KOH} / \mathrm{g}$ after $13 \mathrm{~h}$. The lifetime of this catalyst is over 30 days.

The specification values of biodiesel derived from 3 feedstock oils, as well as 2007 promulgated China BD100 standard were compared and analyzed. In general, the biodiesel generated through this system could satisfactorily meet China BD100 standard. Because the main component of Chinese wood oil is unsaturated 3,a-elaeostearic acid, polymerization reaction may happen during distillation. This results in a much low biodiesel yield for Chinese wood oil. Because trap grease contains a great deal of animal fat, the derived biodiesel has a higher solidification point and pour-point depressant should be added before trap grease biodiesel can be used.

\section{Acknowledgement}

The financial fund received from High Technology R\&D Program (863 project) (2007AA05Z412) and 2006 Guangdong Province Key Technology (200649851301) is much appreciated.

\section{References}

[1] Guo PM, Huang FH, Huang QD. Preparation of biodiesel from waste oil with high acid value. China Oil and Grease 2006;31:66-9.

[2] Ye HD, Ding YD. Process for converting waste animal and plant oils to biodiesel. Chinese patent: CN02115477.5, 2002-12-04.

[3] Wang Y, Ou SY, Liu PZ, Zhang ZS. Preparation of biodiesel from waste cooking oil via two-step catalyzed process. Energy Conversion and Management 2007;48:184-8.

[4] Ji X, Xi XL, Kong LH, Li JF, Li L. Prospect and technology progress of bio-diesel industry. Engineering Science 2002;4:86-93.

[5] Kulkarni MG, Dalai AK. An economical source for biodiesel: a review. Industrial and Engineering Chemistry Research 2006;45:2901-13.

[6] Zhang Y, Dube MA, McLean DD, Kates M. Biodiesel production from waste cooking oil: 1. Process design and technological assessment. Bioresource Technology 2003;89:1-16.

[7] Veljkovic VB, Stamenkovic OS, Todorovic ZB. Fuel 2006;85:2671-5.

[8] Ramadhas AS, Jayaraj S, Muraleedharan C. Biodiesel production from tobacco (Nicotiana tabacum L.) seed oil with a high content of free fatty acids. Fuel 2005;84:335-40.

[9] Felizardo P, Correia MJN, Raposo I. Production of biodiesel from waste frying oils. Waste Management 2006;26:487-94.

[10] Sahoo PK, Das LM, Babu MKG. Biodiesel development from high acid value polanga seed oil and performance evaluation in a $\mathrm{CI}$ engine. Fuel 2006;86:448-54.

[11] Ghadge SV, Raheman H. Biodiesel production from mahua (Madhuca indica) oil having high free fatty acids. Biomass and Bioenergy 2005;28:601-5.

[12] A kind of continuous phase splitter for biodiesel and glycerol, Chinese patent, application No. 200620061332.1.

[13] Freedman B, Butterfield RO, Pryde EH. Transesterification kinectics of soybean oil. Journal of the American Oil Chemists' Society 1986;63:1375-80.

[14] Xie GJ. Preparation of biodiesel from high acid value waste restaurant grease. Technology \& Development of Chemical Industry 2005;34:37-9. 